\title{
Apparent prevalence of Mycoplasma wenyonii, Candidatus Mycoplasma haemobos, and bovine leukemia virus in Wisconsin and Michigan dairy cattle herds
}

\author{
R. A. Schambow, ${ }^{1} \odot$ K. Poulsen, ${ }^{2}$ S. Bolin, ${ }^{3} \odot$ D. Krahn, $^{4}$ B. Norby, ${ }^{5}$ ๑ D. Sockett, ${ }^{2}$ and P. L. Ruegg ${ }^{5 *}$ (1)
}

\section{Graphical Abstract}

Blood samples were collected from 1,930 dairy cows on 64 Wisconsin farms and 591 dairy cows in 18 Michigan farms. Samples were tested for Mycoplasma wenyonii and Candidatus Mycoplasma haemobos using whole-blood UU PCR, and were tested for serum antibodies to bovine leukemia virus using ELISA.

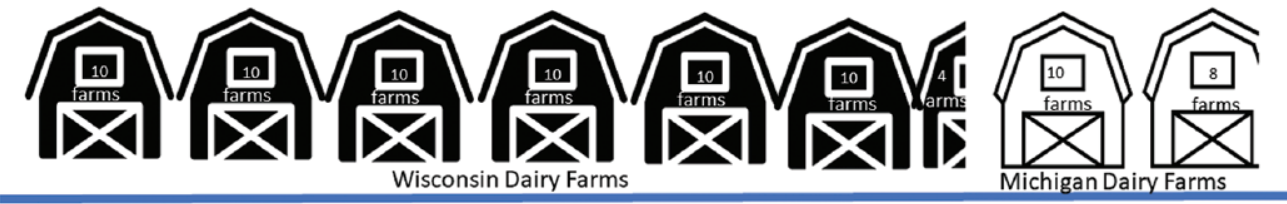

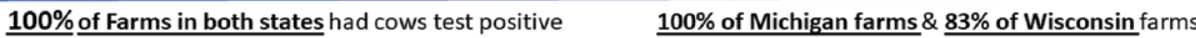

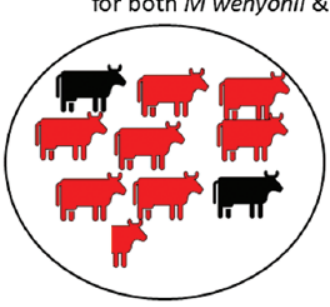

Combined Within Herd Prevalence M. wenyonii $=72 \%$ (23\% to $94 \%)$

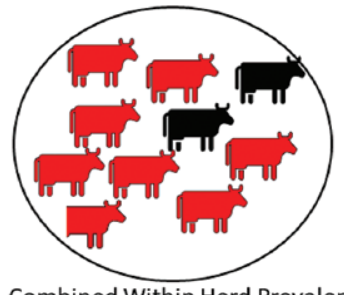

Combined Within Herd Prevalence

C. $M$. haemobos $=78 \%$ $(16 \%$ to $94 \%)$

\section{Summary}

Mycoplasma wenyonii and a related organism, Candidatus Mycoplasma haemobos, have been detected in both ill and apparently healthy cattle, but little is known about their prevalence in US dairy cattle. Blood samples were collected from 1,930 dairy cows on 64 Wisconsin farms and 591 dairy cows in 18 Michigan dairy farms. Samples were tested for Mycoplasma wenyonii and Candidatus Mycoplasma haemobos using whole-blood $\mathrm{PCR}$, and were tested for serum antibodies to bovine leukemia virus using ELISA. This is the first report of the prevalence of hemotrophic mycoplasmas in Wisconsin and Michigan dairy herds and indicates that infection with these organisms is endemic.

\section{Highlights}

- Blood was collected from 1,930 (64) and 591 (18) dairy cows (farms) in Wisconsin and Michigan

- $\quad>70 \%$ of sampled cows and $\geq 5$ cows in all herds tested positive for Mycoplasma wenyonii or Candidatus Mycoplasma haemobos

- All Michigan and $>83 \%$ of Wisconsin herds had $\geq 1$ cow test positive for bovine leukemia virus (BLV)

- Overall prevalence of BLV antibodies was $~ 40 \%$

- Exposure to these organisms was widespread and the effect of infections on animal health and productivity is unknown

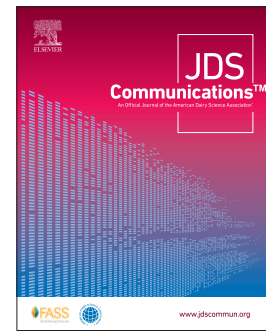

${ }^{1}$ Center for Animal Health and Food Safety, University of Minnesota School of Veterinary Medicine, St. Paul 55108, ${ }^{2}$ Wisconsin Veterinary Diagnostic Lab, Madison 53705, ${ }^{3}$ Department of Pathobiology and Diagnostic Investigation, Michigan State University, East Lansing 48824, ${ }^{4}$ Country Hills Animals Health Center, Fond du Lac, WI 54937, ${ }^{5}$ Department of Large Animal Clinical Sciences, Michigan State University, East Lansing 48824. *Corresponding author: plruegg@msu.edu. @ 2021, The Authors. Published by Elsevier Inc. and Fass Inc. on behalf of the American Dairy Science Association ${ }^{\oplus}$. This is an open access article under the CC BY license (http://creativecommons.org/licenses/by/4.0/). Received September 28, 2020. Accepted November 11, 2020. 


\title{
Apparent prevalence of Mycoplasma wenyonii, Candidatus Mycoplasma haemobos, and bovine leukemia virus in Wisconsin and Michigan dairy cattle herds
}

\author{
R. A. Schambow, ${ }^{1} \odot$ K. Poulsen, ${ }^{2}$ S. Bolin, ${ }^{3} \odot$ D. Krahn, ${ }^{4}$ B. Norby, ${ }^{5} \odot$ D. Sockett, ${ }^{2}$ and P. L. Ruegg ${ }^{5 *} \odot$
}

\begin{abstract}
Mycoplasma wenyonii (formerly Eperythrozoon wenyonii) is a hemotrophic, epicellular bacterial parasite of cattle that has been associated with clinical disorders, including hemolytic anemia, decreased milk yield, and peripheral edema. Mycoplasma wenyonii and a related organism, Candidatus Mycoplasma haemobos, have been detected in both ill and apparently healthy cattle, but little is known about their prevalence in US dairy cattle. The objective of this prospective, cross-sectional study was to determine herd-level apparent prevalence of $M$. wenyonii and C. M. haemobos in dairy cattle located in Wisconsin and Michigan compared with seroprevalence of bovine leukemia virus (BLV) in the same herds. In summer 2018, researchers collected blood samples from 30 lactating cows per herd from randomly recruited farms in selected dairy-intensive counties in each state. During the farm visit, a brief survey was used to collect herd management information. Detection of M. wenyonii and C. M. haemobos were based on PCR testing, and ELISA was used to test for antibodies to BLV. Blood samples were collected from lactating cows located in 64 Wisconsin herds $(\mathrm{n}=1,930$ samples) and 18 Michigan herds $(\mathrm{n}=591$ samples). Herd-level apparent prevalence was $100 \%$ for both $M$. wenyonii and C. M. haemobos. Herd-level seroprevalence for BLV was 83 and $100 \%$ for Wisconsin and Michigan herds, respectively. Estimated within-herd apparent prevalence of M. wenyonii was $71.7 \% \pm 1.0 \%$ (ranging from 23.3 to $93.5 \%$ ) and for C. M. haemobos was $77.3 \% \pm 1.0 \%$ (ranging from 16.7 to $100 \%$ ). Within-herd prevalence of BLV positive samples was $39.8 \% \pm 1.0 \%$ and ranged from 0 to $86.7 \%$. About $22 \%$ of cows were concurrently positive for all 3 organisms. Parity and stage of lactation were recorded for 2,317 cows. Prevalence of positive cows for parity groups 1,2 , and $\geq 3$ were $72.0,73.8$, and $67.7 \%$ for $M$. wenyonii; $80.9,76.8$, and $74.9 \%$ for C. M. haemobos; and 25.3, 39.7, and 55.5\% for BLV, respectively. None or only minor differences in apparent prevalence were observed based on stage of lactation. This is the first report of the prevalence of hemotrophic mycoplasmas in Wisconsin and Michigan dairy herds and indicates that infection with these organisms is endemic. The impact of infection on cattle health and productivity remains unknown, and risk factors associated with infection warrant further study.
\end{abstract}

$\mathrm{H}$ emotrophic mycoplasmas (hemoplasmas) lack a cell wall and have a tropism for mammalian red blood cells. They have been found in many species, including dogs and cats (Messick, 2003), swine (Gatto et al., 2019), small ruminants (Aktas and Ozubek, 2017), reindeer (Stoffregen et al., 2006) and cattle (Strugnell and McAuliffe, 2012; de Mello et al., 2019). Hemoplasma infections have been found in healthy animals as well as being associated with a range of clinical signs, including chronic subclinical to life-threatening hemolytic anemia (Genova et al., 2011; McFadden et al., 2016), production loss (Tagawa et al., 2013), and infertility (Montes et al., 1994), depending on the species of hemoplasma and immune state of the individual (Strugnell and McAuliffe, 2012). Researchers have proposed that these organisms may even be important cofactors in the development of secondary infections and neoplastic diseases, such as in cats infected concurrently with Haemobartonella felis (now named Mycoplasma hemofelis) and feline leukemia virus (Bobade et al., 1988).

Mycoplasma wenyonii, formerly known as Eperythrozoon wenyonii (Neimark et al., 2002), and Candidatus Mycoplasma haemobos are both hemotrophic, epicellular bacterial parasites. Mycoplasma wenyonii was first identified in a splenectomized calf in 1934 (Adler and Ellenbogen, 1934) and has since been identified in several countries (dos Santos et al., 2012; McFadden et al., 2016; Quiroz-Castañeda et al., 2018; Díaz-Sánchez et al., 2019; Nouvel et al., 2019). Based on phylogenetic evidence and its $16 \mathrm{~S}$ ribosomal RNA gene sequence, it was recently reclassified into the Mycoplasma genus (Ayling et al., 2012). Various clinical signs have been associated with $M$. wenyonii infection in cattle, including hemolytic anemia, pyrexia, infertility, decreased milk production, prefemoral lymphadenopathy, rough haircoat, weight loss, and scrotal, teat, and hind limb edema (Strugnell and McAuliffe, 2012). Chronic infection with $M$. wenyonii or C. M. haemobos, or co-infection have been associated with decreased milk production (Tagawa et al., 2013). Diagnosis was traditionally made via microscopic visualization of organisms on acridine orange- or Giemsastained blood smears, but these methods are of low sensitivity and specificity for hemotrophic bacterium (Ritzmann et al., 2009), and PCR is now the preferred method of diagnosis (Hoelzle et al.,

\footnotetext{
${ }^{1}$ Center for Animal Health and Food Safety, University of Minnesota School of Veterinary Medicine, St. Paul 55108, ${ }^{2}$ Wisconsin Veterinary Diagnostic Lab, Madison 53705, ${ }^{3}$ Department of Pathobiology and Diagnostic Investigation, Michigan State University, East Lansing $48824,{ }^{4}$ Country Hills Animals Health Center, Fond du Lac, WI 54937, ${ }^{5}$ Department of Large Animal Clinical Sciences, Michigan State University, East Lansing 48824. *Corresponding author: plruegg@msu.edu. @ 2021, The Authors. Published by Elsevier Inc. and Fass Inc. on behalf of the American Dairy Science Association ${ }^{\oplus}$. This is an open access article under the CC BY license (http://creativecommons.org/licenses/by/4.0/). Received September 28, 2020. Accepted November 11, 2020.
} 
2011). When clinical signs are present, treatment with oxytetracycline has reportedly resulted in resolution of signs in some animals (Montes et al., 1994; Genova et al., 2011). Hemotrophs are transmitted via blood, and arthropod vectors and direct contact of blood via fomites have been suggested as possible sources (Smith et al., 1990). Vertical transmission has also been shown, but its overall significance as a route of transmission remains unknown (Hornok et al., 2011; Sasaoka et al., 2015; Niethammer et al., 2018).

Hemoplasmas have been identified in apparently healthy cattle (Strugnell and McAuliffe, 2012), but the clinical relevance of subclinical infection with $M$. wenyonii and $C$. M. haemobos remains largely unknown. This study was undertaken to estimate prevalence of $M$. wenyonii and C. M. haemobos via PCR compared with seroprevalence of bovine leukemia virus (BLV) in the same herds and to generate preliminary data to identify potential risk factors (including within-herd prevalence of BLV) for infection and transmission in dairy cattle herds in selected regions of Wisconsin and Michigan.

The study was designed as a prospective, cross-sectional study, with herd as the primary experimental unit. Herds in selected dairy-intensive counties in Michigan and Wisconsin containing a minimum of 50 lactating dairy cows were eligible for inclusion in the study. Selection of herds was stratified by herd size to reflect the herd size distribution in the Upper Midwest region, where approximately $60 \%$ of eligible herds contain $\geq 200$ cows (larger herds) and $40 \%$ of eligible herds contain $<200$ cows (small herds) (https://quickstats.nass.usda.gov/). Herds were initially selected using a random number generator from among all herds on the dairy permit and confined animal feeding operation permit lists of the top 10 Wisconsin dairy cow counties (based on number of dairy cows), and then mailed a letter containing a prepaid return postcard informing them of the study. In Michigan, randomly selected herds in 10 counties were mailed a recruitment letter using a similar process. Producers who returned the postcard indicating willingness to participate were contacted by phone to schedule a sampling visit. Within-herd, a sample size of 30 cows per herd was calculated to detect $\geq 10 \%$ prevalence of infected cows with $95 \%$ confidence.

Each herd was visited once for sampling between July and August 2018. All lactating cows were eligible for sampling, regardless of breed, parity, production, stage of lactation, or reproductive status. To alleviate producer concerns about time demands related to searching for randomly selected cows on very large dairy farms, during the farm visit, researchers selected a convenience sample of healthy cows that were distributed among all cattle pens and age groups. Study personnel collected whole blood samples from the coccygeal vessels of about 30 cows using $10-\mathrm{mL}$ serum-separator and EDTA tubes. After sampling, parity, and stage of lactation for each sampled cow were collected from herd records. Blood samples were immediately cooled to $4^{\circ} \mathrm{C}$ for transport to the Michigan State University Veterinary Diagnostic Laboratory (Lansing, MI) for processing.

Immediately following sample collection, a brief questionnaire (available from the authors) was given to an owner or manager of each farm with the purpose of identifying preliminary data about potential risk factors related to the epidemiology of $M$. wenyonii, C. M. haemobos, and BLV. General questions were asked about housing, feeding, and husbandry, vaccination and treatment protocols, and reproductive management. This study was approved by the Institutional Animal care and Use Committee at Michigan State University (09-17-155-00) and was deemed exempt from human subjects requirements by the Institutional Review Board at Michigan State University (IRB x17-1538e).

Whole blood harvested into evacuated tubes containing EDTA was used for DNA extraction. A commercial kit (Quick-DNA Miniprep Plus Kit, Zymo Research, Irvine, CA) was used to extract DNA from $200 \mu \mathrm{L}$ of blood following kit instructions. The kit uses a silica-based DNA purification method, and the purified DNA was eluted with $75 \mu \mathrm{L}$ of elution buffer supplied with the kit. The eluted DNA was used in a PCR assay targeting the 16S ribosomal RNA gene of $M$. wenyonii and C. M. haemobos. The amplification products differed by $13 \mathrm{bp}$, which was sufficient to allow detection of mixed infections and identification of individual hemoplasma (Jensen et al., 2001; Tagawa et al., 2008). The PCR reaction used AmpliTaq Gold 360 Master Mix (Applied Biosystems, Foster City, $\mathrm{CA}$ ). The reaction conditions were $95^{\circ} \mathrm{C}$ for $5 \mathrm{~min}$ followed by 40 cycles of $95^{\circ} \mathrm{C}$ for $30 \mathrm{~s}, 56^{\circ} \mathrm{C}$ for $30 \mathrm{~s}$, and $72^{\circ} \mathrm{C}$ for $30 \mathrm{~s}$, followed by $72^{\circ} \mathrm{C}$ for $5 \mathrm{~min}$. An agarose-based electrophoresis system and ethidium bromide staining was used for detection of amplified product. Representative PCR products, at least 3 from each herd, were processed using ExoSAP-IT Express (Life Technologies Corp., Carlsbad, CA) and submitted to the Research Technology Support Facility at Michigan State University for Sanger sequencing to verify identity. To reduce risk of cross-contamination during the PCR assays, reagent preparation, nucleic acid extraction, addition of sample DNA to the PCR reaction tubes, and the PCR assay all were done in separate rooms with dedicated supplies and laboratory gowns.

Detection of antibody against the bovine leukemia virus viral glycoprotein 51 (gp51) was done using commercially available ELISA kit (Bovine Leukemia Virus Antibody Test Kit, VMRD Inc., Pullman, WA) following the manufacturer's recommendations for performance and interpretation of results.

Descriptive data were reviewed and evaluated for normality, and associations between herd characteristics and state were determined using either ANOVA (continuous variables) or Chi-squared tests (categorical variables). Within-herd apparent prevalence was calculated for each state and for the combined data. Both ranksum and $t$-tests were used to compare prevalence of organisms (M. wenyonii or C. M. haemobos) and antibodies (BLV) between states. After determining that the organisms were endemic, data from all herds was combined, and cow-level data were used as the experimental unit to test associations between prevalence of organisms or antibodies and parity or stage of lactation. Parity was categorized into 3 groups: parity 1, 2 and $\geq 3$, and stage of lactation was categorized as 0 to 68,69 to 140,141 to 239 , and $\geq 240$ DIM. Associations between parity group or stage of lactation group and prevalence of organisms were evaluated by Bartlett's test for equal variances, and separation among least squares means was performed using Bonferroni tests. Associations between apparent prevalence and selected risk factors were evaluated using ANOVA. Statistical analysis was performed using SAS v9.4 (SAS Institute Inc., Cary, NC); statistical significance was declared at $P<0.05$ and trends were defined at $P<0.10$.

Recruitment letters were sent to 375 of about 3,000 dairy farms located in the 10 selected dairy-intensive counties in Wisconsin, and 113 producers $(30.1 \%)$ returned postcards indicating that they 
were interested in participating. Ultimately, 64 Wisconsin farms were enrolled based on ease of scheduling visits. In Michigan, letters were sent to 120 of about 600 dairy farms located in 10 counties, and 18 farms (15.0\%) responded affirmatively and were enrolled. Enrolled herds together contained about 88,133 lactating and dry cows, 9,554 preweaning calves, and 40,363 replacement heifers. The median number of mature cows per herd was 350 , but herds ranged in size from 56 to 8,833 mature cows ( mean $=1,075$ \pm 176 ). Most management practices and farm characteristics did not vary by state $(P \geq 0.10)$ but Wisconsin herds contained fewer purchased cattle $(2.4 \%$ of Wisconsin cows and $8.8 \%$ of Michigan cows; $P=0.003)$ and slightly more primiparous cows $(31.1 \%$ for Michigan and $37.5 \%$ for Wisconsin herds; $P=0.011$ ). Typical of dairy farms in the Upper Midwest, cows were primarily housed in freestalls ( $81 \%$ of farms), but tiestalls were used on $17 \%$ of farms (all in Wisconsin), and 2 Wisconsin farms used loose housing for some adult cows. About $36 \%$ of farms gave some groups of cattle at least occasional access to pasture. Almost all cows were fed a TMR and $57 \%$ of farms milked cows at least 3 times per day. Fly control was reported to be used extensively for both calves and cows. Calf housing was more variable than housing of adult cows and included outdoor hutches $(40 \%)$, individual pens in indoor calf barns (25\%), indoor group pens (14\%), and combinations of the former $(22 \%)$. Based on estimates provided during the survey, beginning at birth, the typical mature cow had received a total of $65.4 \pm 5.7$ injections (inclusive of vaccines, oxytocin, supplements, and reproductive hormones but not treatments). Almost $80 \%$ of interviewees reported that they used needles on more than one animal and estimated that the average needle was used for 15.1 \pm 2.6 injections. Similarly, most farmers reported using palpation sleeves on multiple animals.

Blood samples $(\mathrm{n}=2,521)$ were collected from mature cows located in Wisconsin herds $(\mathrm{n}=1,930$ samples; median of 30.0 per farm; ranging from 30 to 41$)$ and Michigan herds ( $\mathrm{n}=591$ samples; median of 30.5 samples per farm; ranging from 30 to 32). Mycoplasma wenyonii and C. M. haemobos were identified by PCR in blood samples obtained from at least 5 cows in all herds (herd-level apparent prevalence of 100\%). Overall, within-herd apparent prevalence of $M$. wenyonii was (mean $\pm \mathrm{SE}$ ) $71.7 \% \pm 1.0 \%$ and ranged from 23.3 to $93.5 \%$. Overall apparent prevalence of $C$. M. haemobos was $77.3 \% \pm 1.0 \%$ and ranged from 16.7 to $100 \%$. At least $1 \mathrm{BLV}$ positive blood sample was found in $83 \%$ of Wisconsin herds and $100 \%$ of Michigan herds. Overall prevalence of BLV antibodies was $39.8 \% \pm 1.0 \%$ and ranged from 0 to $86.7 \%$. Withinherd apparent prevalence of $M$. wenyonii was greater for cows sampled in Michigan herds $(76.5 \% \pm 1.7 \%)$ than in Wisconsin herds $(70.1 \% \pm 1.0 \% ; P=0.003)$. In contrast, within-herd apparent prevalence of $C$. M. haemobos did not vary between states and was $78.9 \% \pm 1.7 \%$ and $76.8 \% \pm 1.0 \%$ for cows sampled in Michigan and Wisconsin, respectively $(P=0.30)$. Likewise, within-herd apparent prevalence of BLV did not vary between states and was $41.5 \% \pm 2.0 \%$ and $39.3 \% \pm 1.1 \%$ for cows in Michigan and Wisconsin herds, respectively $(P=0.36)$. About $22 \%$ of cows were concurrently positive for both organisms and BLV antibodies, and this prevalence did not vary by state $(P=0.49)$

Parity was recorded for 807,696 , and 814 cows in parities 1,2 , and $\geq 3$, respectively (Figure 1). The apparent prevalence of cows positive for $M$. wenyonii was less for cows in parity group $\geq 3$ com-

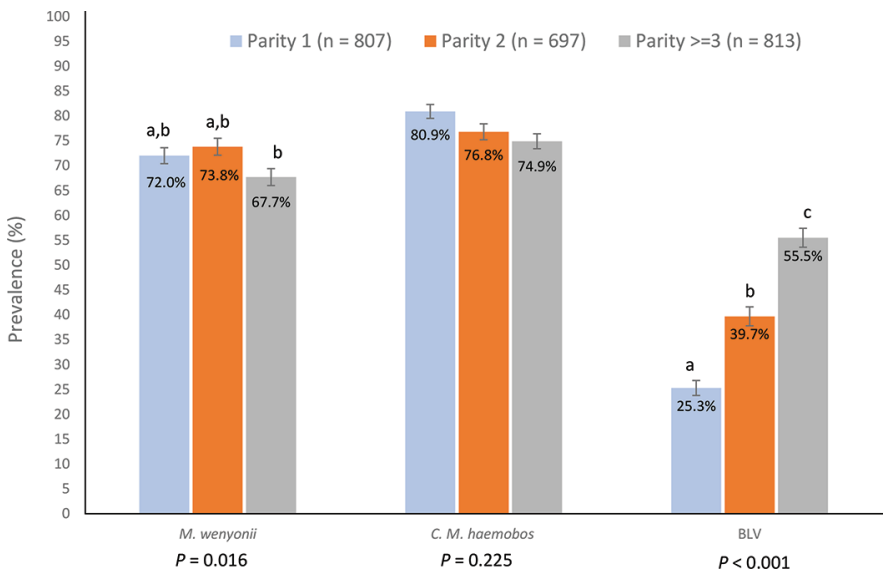

Figure 1. Prevalence of positive hemotrophic mycoplasma PCR tests for Mycoplasma wenyonii and Candidatus Mycoplasma haemobos and serum bovine leukemia virus (BLV) antibody tests by parity for dairy cows sampled in Wisconsin ( $n=64)$ and Michigan $(n=18)$ herds. Differing letters $(a-c)$ denote significant differences among parities within organism; SE denoted by error bars. $P$-value derived from Bartlett's test of equal variances.

pared with that in primiparous cows $(P=0.03)$ but did not differ between primiparous cows and cows in their second lactation $(P$ > 0.16). Similarly, apparent prevalence of cows positive for C. $M$. haemobos was less for cows in parity group $\geq 3$ compared with other parity groups $(P=0.01)$ but did not differ between parity groups 1 and $2(P>0.16)$. As previously reported (Erskine et al., 2012), prevalence of BLV-positive blood samples increased with parity group (Figure $1, P<0.001$ ).

Stage of lactation (DIM) was recorded for 1,970 lactating cows and dry cows and ranged from 0 (23 dry cows) to $682 \mathrm{~d}$ (Figure 2). There was no association between stage of lactation and apparent prevalence of $M$. wenyonii $(P=0.40)$ or apparent prevalence of BLV antibodies $(P=0.86$; Figure 2$)$. The apparent prevalence of C. M. haemobos was less for cows in early lactation $(70.0 \%$ for $0-68$ DIM) than for cows in all other stages of lactation (80.0, 82.4 , and $78.1 \%$ for $69-140141-239$, and $>240$ DIM, respectively, $P<0.001$; Figure 2).

Although this was an exploratory study with the primary objective of determining prevalence of hemotrophic mycoplasma organisms, to provide direction for future studies with more herds we performed a preliminary bivariate analysis to determine relationships between putative risk factors and apparent prevalence of hemotrophic mycoplasma and BLV (Table 1). No associations were seen between apparent prevalence of any organism and herdsize category or use of rectal sleeves on $>1$ cow. Among organisms, there was a tendency for lower within-herd apparent prevalence only of $M$. wenyonii for herds that did not allow access of any cattle to pasture $(P=0.09)$ and for herds that reported purchase of $\geq 1$ animals (Table $1 ; P=0.07$ ). Within-herd apparent prevalence of BLV tended to be greater for herds that reported using $>1$ needle per cow $(P=0.08)$. Within-herd apparent prevalence was greater for both $M$. wenyonii and C. M. haemobos when cattle were housed in herds that contained BLV-positive animals, but all BLV-negative herds were located in Wisconsin, so that association is confounded by state (Table $1 ; P<0.05$ ). We identified an interesting potential 
Table 1. Apparent prevalence of hemotrophic mycoplasmas ${ }^{1}$ and bovine leukemia virus (BLV) serum antibodies for selected herd characteristics

\begin{tabular}{|c|c|c|c|c|}
\hline \multirow[b]{2}{*}{ Risk factor } & \multicolumn{4}{|c|}{ Within-herd apparent prevalence, \% (SE) } \\
\hline & M. wenyonii & C.M. haemobos & BLV & All 3 organisms \\
\hline \multicolumn{5}{|c|}{ Herd size (no. of milking and dry cows) } \\
\hline$>1,000(n=27)$ & $0.70(0.02)$ & $0.79(0.02)$ & $0.46(0.04)$ & $0.24(0.03)$ \\
\hline$P$-value among categories & 0.78 & 0.67 & 0.26 & 0.79 \\
\hline \multicolumn{5}{|l|}{ Animals on pasture } \\
\hline$P$-value among categories & 0.09 & 0.67 & 0.65 & 0.15 \\
\hline \multicolumn{5}{|l|}{ Closed herd } \\
\hline Yes $(n=36)$ & $0.75(0.02)$ & $0.76(0.02)$ & $0.41(0.04)$ & $0.23(0.03)$ \\
\hline No $(n=46)$ & $0.69(0.02)$ & $0.78(0.02)$ & $0.39(0.03)$ & $0.21(0.02)$ \\
\hline$P$-value among categories & 0.07 & 0.38 & 0.72 & 0.61 \\
\hline \multicolumn{5}{|l|}{ Cows palpated per rectal sleeve } \\
\hline $1(n=28)$ & $0.73(0.03)$ & $0.74(0.02)$ & $0.37(0.04)$ & $0.21(0.03)$ \\
\hline$P$-value among categories & 0.89 & 0.32 & 0.08 & 0.24 \\
\hline \multicolumn{5}{|l|}{ BLV-positive herd } \\
\hline Yes $(n=71)$ & $0.74(0.02)$ & $0.78(0.04)$ & & \\
\hline No $(n=11)$ & $0.58(0.04)$ & $0.70(0.02)$ & & \\
\hline$P$-value among categories & 0.001 & 0.05 & & \\
\hline \multicolumn{5}{|l|}{ Calf housing } \\
\hline Outdoor hutch $(\mathrm{n}=32)$ & $0.74(0.03)$ & $0.81^{\mathrm{a}}(0.02)$ & $0.45(0.04)$ & $0.26(0.03)$ \\
\hline Indoor individual $(\mathrm{n}=20)$ & $0.65(0.03)$ & $0.70^{\mathrm{b}}(0.03)$ & $0.34(0.05)$ & $0.17(0.04)$ \\
\hline Indoor group $(n=11)$ & $0.76(0.05)$ & $0.78^{\mathrm{ab}}(0.04)$ & $0.49(0.07)$ & $0.29(0.05)$ \\
\hline Other or various $(n=18)$ & $0.72(0.04)$ & $0.79^{\mathrm{ab}}(0.03)$ & $0.33(0.05)$ & $0.18(0.04)$ \\
\hline$P$-value among categories & 0.13 & 0.01 & 0.10 & 0.10 \\
\hline
\end{tabular}

${ }^{a, b}$ Means with differing letters indicate significant differences among categories within agent. $P$-values were derived from ANOVA and corrected using Bonferroni tests.

${ }^{1}$ Mycoplasma wenyonii and Candidatus Mycoplasma haemobos.

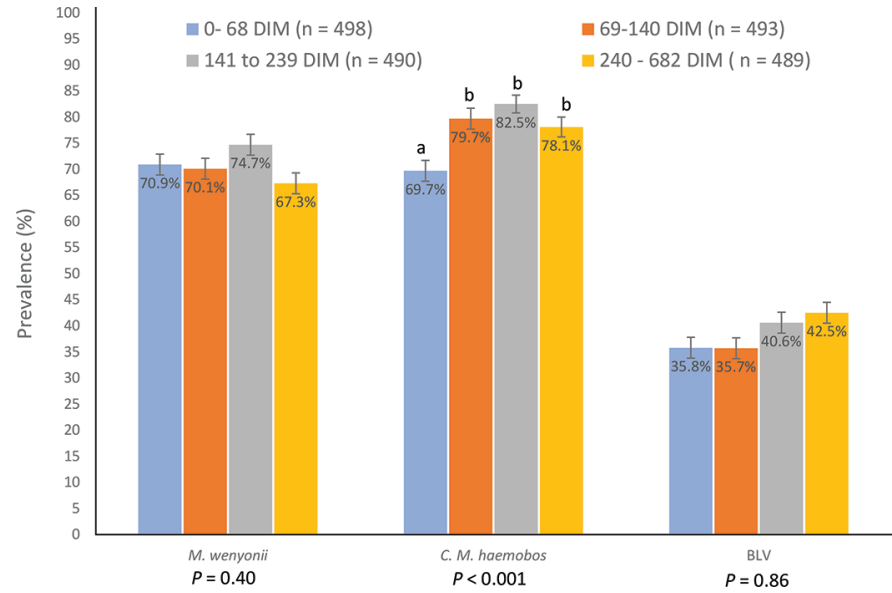

Figure 2. Prevalence of positive hemotrophic mycoplasma PCR tests for Mycoplasma wenyonii and Candidatus Mycoplasma haemobos and serum bovine leukemia virus (BLV) antibody tests by stage of lactation for dairy cows sampled in Wisconsin $(n=64)$ and Michigan $(n=18)$ herds. Differing letters $(a, b)$ denote significant differences among stage of lactation groups within organism; SE denoted by error bars. $P$-value derived from Bartlett's test of equal variances. association of within-herd apparent prevalence and calf housing (Table 1). Cows in herds that used only indoor individual calf housing had a lower apparent prevalence of C. M. haemobos than herds that used outdoor hutches only (Table 1). Although this association was not statistically significant for other organisms (or BLV antibodies), the same numerical trend was seen, indicating that further investigation of the role of outdoor calf housing and infection with blood borne agents should be considered in studies that include more herds and have greater statistical power. It is important to note that this study was not designed to have sufficient power for a risk factor analysis, so potential risk factors noted in this study warrant further investigation.

To our knowledge, this is the first prevalence study of hemotrophic mycoplasmas in dairy herds located Wisconsin and Michigan, and it indicates that infection is endemic in these 2 states. The endemic nature of the infections and high within-herd prevalence were unexpected, and more research is urgently needed to identify the effect of these infections and the risk factors associated with infection. Herds that participated in this study volunteered after randomly receiving recruitment letters, so it is possible that selection bias may have influenced our results, but the $100 \%$ herd-level prevalence is highly suggestive that infection with these organisms is widely distributed in these northern states. The impact of infection with hemoplasmas on health, well-being, and productivity of 
dairy cows is not well defined. Hemoplasmas have been associated with several vague clinical syndromes of cattle in several countries (Tagawa et al., 2008; Genova et al., 2011; Hoelzle et al., 2011; Strugnell et al., 2011; Yuan et al., 2011; Ayling et al., 2012; Gladden et al., 2016). Clinical signs have included immunemediated anemia, edema of the mammary gland and rear legs, pyrexia, lymphadenopathy, reduced milk yield, weight loss, and infertility (Smith et al., 1990; Montes et al., 1994; Scott, 2008; Genova et al., 2011; Hoelzle et al., 2011; Strugnell et al., 2011; Gladden et al., 2016). In the United States, the first apparent case of Eperythrozoon wenyonii was reported in Colorado in 1990, using blood smears to diagnose the disease in a group of primiparous dairy cows in a large dairy farm (Smith et al., 1990). The animals were reported to have edema in the teats and distal limbs, prefemoral lymphadenopathy, fever, reduced milk yield, weight loss, and reproductive inefficiency. In 1994, a young Charolais bull in Oklahoma was diagnosed with transient infertility after experiencing clinical signs of scrotal and hindlimb edema accompanied by fever, lethargy, and anemia (Montes et al., 1994). The diagnosis was made based on observation of large numbers of $E$. wenyonii on blood smears. Similar signs of disease have been associated with C. M. haemobos and co-infection with both $M$. wenyonii and $C$. M. haemobos (Tagawa et al., 2008; Hoelzle et al., 2011). Chronic subclinical infection with these organisms has been associated with reduced milk yield (Tagawa et al., 2013). Although infection with these organisms has been demonstrated to be associated with occurrence of specific clinical signs, the organisms have also been identified in blood of apparently healthy animals (Strugnell et al., 2011; Yuan et al., 2011; McFadden et al., 2016), and research on the duration and impact of infection in dairy cows is needed.

Our data did not demonstrate consistent trends associating apparent prevalence with parity or stage of lactation, but the high prevalence in primiparous cows and lack of increasing prevalence with stage of lactation suggest that infection may have occurred before initiating lactation. While prevalence of hemotrophic mycoplasma was the subject of our research, we evaluated seroprevalence of BLV because we hypothesized that transmission mechanisms may be similar, and understanding BLV prevalence may help identify potential risk factors for further study. However, in contrast to the typical increased prevalence of BLV as cows age, we observed slightly lower apparent prevalence for $M$. wenyonii only in parity group $\geq 3$. Apparent prevalence of BLV increased with parity but was significantly lower than that of the hemotrophs. We detected hemoplasmas using PCR and detected the presence of BLV based on serum antibodies, so comparisons should be made very cautiously. We hypothesize that the transmission mechanisms should be similar, but it is possible that clearance of hemoplasma is enhanced with age or that the concentration of hemoplasma organisms decreases with age, thus reducing the sensitivity of detection. Future studies should include sampling of youngstock beginning at birth and, to discern the role of vertical transmission, should include dam and calf pairs. Given the endemic nature of infection and high within-herd prevalence in both states, longitudinal studies are needed to identify the role of calf housing, flies, and other potential vectors.

Transmission of hemoplasmas is through contact with blood, but the ability of other bodily fluids to infect susceptible hosts is not known (Strugnell and McAuliffe, 2012). Bloodborne transmis- sion is thought to occur primarily through use of common needles, rectal palpation sleeves, and other fomites such as tools used for dehorning and hoof-trimming (Strugnell and McAuliffe, 2012). Our small study was not able to confirm associations between the use of common needles or palpation sleeves; larger studies that include herds with lower apparent prevalence are needed to better define the risk factors for infection. Authors of a case report suggested that the incidence of positive animals was greater in summer and fall and suggested that transmission by arthropod vectors may have been responsible, but they could not confirm a causal relationship (Strugnell and McAuliffe, 2012). Given that all herds enrolled in this study were in northern regions, transmission by arthropod vectors would be unlikely for at least 3 to 4 mo of the year, restricting the ability of these insects to consistently contribute to transmission. Although lice (Hofmann-Lehmann et al., 2004), house flies, stable flies, and horn flies (Hornok et al., 2011) have all been demonstrated to be capable of infection and mechanical transmission, the ability of blood-sucking insects to serve as reservoirs is unknown (Hornok et al., 2011). Vertical transmission has been demonstrated to occur for both M. wenyonii and C. M. haemobos, but the clinical significance of fetal infection is not known (Sasaoka et al., 2015). Infection with these organisms is increasingly being recognized by dairy practitioners in Michigan and Wisconsin, and broader studies are needed as a first step in evaluating the risk of this disease to health and productivity of dairy cattle.

\section{References}

Adler, S., and V. Ellenbogen. 1934. A note on two new blood parasites of cattle, Eperythrozoon and Bartonella. J. Comp. Pathol. Ther. 47:219-221. https:// doi.org/10.1016/S0368-1742(34)80027-6.

Aktas, M., and S. Ozubek. 2017. A molecular survey of small ruminant hemotropic mycoplasmosis in Turkey, including first laboratory confirmed clinical cases caused by Mycoplasma ovis. Vet. Microbiol. 208:217-222. https://doi.org/10.1016/j.vetmic.2017.08.011.

Ayling, R. D., S. Bisgaard-Frantzen, A. Adler, R. W. Blowey, A. M. Barlow, M. F. Millar, and G. M. van der Burgt. 2012. Detection of Candidatus Mycoplasma haemobos, Mycoplasma wenyonii and Anaplasma phagocytophilum from cattle in England. Vet. Rec. 170:543. https://doi.org/10 $.1136 /$ vr. 100636 .

Bobade, P. A., A. S. Nash, and P. Rogerson. 1988. Feline haemobartonellosis: Clinical, haematological and pathological studies in natural infections and the relationship to infection with feline leukaemia virus. Vet. Rec. 122:32-36. https://doi.org/10.1136/vr.122.2.32.

de Mello, V. V. C., I. A. de Souza Ramos, H. M. Herrera, N. S. Mendes, A. C. Calchi, J. B. V. Campos, G. C. Macedo, J. V. A. Alves, R. Z. Machado, and M. R. André. 2019. Occurrence and genetic diversity of hemoplasmas in beef cattle from the Brazilian Pantanal, an endemic area for bovine trypanosomiasis in South America. Comp. Immunol. Microbiol. Infect. Dis. 66:101337. https://doi.org/10.1016/j.cimid.2019.101337.

Díaz-Sánchez, A. A., B. Corona-González, M. L. Meli, D. O. Álvarez, E. V. Cañizares, O. F. Rodríguez, E. L. Rivero, and R. Hofmann-Lehmann. 2019. First molecular evidence of bovine hemoplasma species (Mycoplasma spp.) in water buffalo and dairy cattle herds in Cuba. Parasit. Vectors 12:78. https://doi.org/10.1186/s13071-019-3325-y.

dos Santos, A. P., A. M. Guimaraes, N. C. do Nascimento, P. J. SanMiguel, and J. B. Messick. 2012. Complete genome sequence of Mycoplasma wenyonii strain Massachusetts. J. Bacteriol. 194:5458-5459. https://doi.org/10.1155/ 2012/350374.

Erskine, R. J., P. C. Bartlett, T. M. Byrem, C. L. Render, C. Febvay, and J. T. Houseman. 2012. Using a herd profile to determine age-specific apparent prevalence of bovine leukemia virus in Michigan dairy herds. Vet. Med. Int. 2012:350374. https://doi.org/10.1155/2012/350374.

Gatto, I. R. H., K. Sonálio, R. B. D. Amaral, N. Morés, O. A. Dalla Costa, M. R. André, and L. G. de Oliveira. 2019. High frequency and molecular charac- 
terization of porcine hemotrophic mycoplasmas in Brazil. Vet. Microbiol. 231:33-39. https://doi.org/10.1016/j.vetmic.2019.02.024.

Genova, S. G., R. N. Streeter, K. E. Velguth, T. A. Snider, K. M. Kocan, and K. M. Simpson. 2011. Severe anemia associated with Mycoplasma wenyonii infection in a mature cow. Can. Vet. J. 52:1018-1021.

Gladden, N., H. Haining, L. Henderson, F. Marchesi, L. Graham, M. McDonald, F. R. Murdoch, A. Bruguera Sala, J. Orr, and K. Ellis. 2016. A case report of Mycoplasma wenyonii associated immune-mediated haemolytic anaemia in a dairy cow. Ir. Vet. J. 69:1. https://doi.org/10.1186/s13620-016 -0061-x.

Hoelzle, K., M. Winkler, M. M. Kramer, M. M. Wittenbrink, S. M. Dieckmann, and L. E. Hoelzle. 2011. Detection of Candidatus Mycoplasma haemobos in cattle with anaemia. Vet. J. 187:408-410. https://doi.org/10.1016/j.tvj1 2010.01.016

Hofmann-Lehmann, R., M. L. Meli, U. M. Dreher, E. Gonczi, P. Deplazes, U. Braun, M. Engels, J. Schupbach, K. Jorger, R. Thoma, C. Griot, K. D. Stark, B. Willi, J. Schmidt, K. M. Kocan, and H. Lutz. 2004. Concurrent infections with vector-borne pathogens associated with fatal hemolytic anemia in a cattle herd in Switzerland. J. Clin. Microbiol. 42:3775-3780. https://doi.org/10.1128/JCM.42.8.3775-3780.2004.

Hornok, S., A. Micsutka, M. L. Meli, H. Lutz, and R. Hofmann-Lehmann. 2011. Molecular investigation of transplacental and vector-borne transmission of bovine haemoplasmas. Vet. Microbiol. 152:411-414. https://doi .org/10.1016/j.vetmic.2011.04.031

Jensen, W. A., M. R. Lappin, S. Kamkar, and W. J. Reagan. 2001. Use of a polymerase chain reaction assay to detect and differentiate two strains of Haemobartonella felis in naturally infected cats. Am. J. Vet. Res. 62:604-608. https://doi.org/10.2460/ajvr.2001.62.604.

McFadden, A., H. J. Ha, J. J. Donald, I. M. Bueno, M. van Andel, J. C. Thompson, D. J. Tisdall, and D. J. Pulford. 2016. Investigation of bovine haemoplasmas and their association with anaemia in New Zealand cattle. N. Z. Vet. J. 64:65-68. https://doi.org/10.1080/00480169.2015.1090356.

Messick, J. B. 2003. New perspectives about Hemotrophic mycoplasma (formerly, Haemobartonella and Eperythrozoon species) infections in dogs and cats. Vet. Clin. North Am. Small Anim. Pract. 33:1453-1465. https:/ /doi.org/10.1016/j.cvsm.2003.08.002.

Montes, A. J., D. F. Wolfe, E. G. Welles, J. W. Tyler, and E. Tepe. 1994. Infertility associated with Eperythrozoon wenyonii infection in a bull. J. Am. Vet. Med. Assoc. 204:261-263.

Neimark, H., K. E. Johansson, Y. Rikihisa, and J. G. Tully. 2002. Revision of haemotrophic Mycoplasma species names. Int. J. Syst. Evol. Microbiol. 52:683. https://doi.org/10.1099/00207713-52-2-683.

Niethammer, F. M., J. Ade, L. E. Hoelzle, and B. Schade. 2018. Hemotrophic mycoplasma in Simmental cattle in Bavaria: Prevalence, blood parameters, and transplacental transmission of 'Candidatus Mycoplasma haemobos' and Mycoplasma wenyonii. Acta Vet. Scand. 60:74. https://doi.org/10 $.1186 / \mathrm{s} 13028-018-0428-\mathrm{y}$.

Nouvel, L. X., M. C. Hygonenq, G. Catays, E. Martinelli, P. Le Page, É. Collin, H. Inokuma, F. Schelcher, C. Citti, and R. Maillard. 2019. First detection of Mycoplasma wenyonii in France: Identification, evaluation of the clinical impact and development of a new specific detection assay. Comp. Immunol. Microbiol. Infect. Dis. 63:148-153. https://doi.org/10.1016/j.cimid .2019.01.010.
Quiroz-Castañeda, R. E., F. Martínez-Ocampo, and E. Dantán-González. 2018 Draft genome sequence of Mycoplasma wenyonii, a second hemotropic mycoplasma species identified in Mexican bovine cattle. Microbiol. Resour. Announc. 7:e00875-18. https://doi.org/10.1128/MRA.00875-18.

Ritzmann, M., J. Grimm, K. Heinritzi, K. Hoelzle, and L. E. Hoelzle. 2009. Prevalence of Mycoplasma suis in slaughter pigs, with correlation of PCR results to hematological findings. Vet. Microbiol. 133:84-91. https://doi .org/10.1016/j.vetmic.2008.06.015.

Sasaoka, F., J. Suzuki, T. Hirata, T. Ichijo, K. Furuhama, R. Harasawa, and H. Satoh. 2015. Vertical transmission of Mycoplasma wenyonii in cattle, supported by analysis of the ribonuclease P RNA gene- Short communication. Acta Vet. Hung. 63:271-274. https://doi.org/10.1556/004.2015.025.

Scott, R. 2008. Distal hind limb and udder oedema of dairy cattle associated with an unidentified haemotrophic bacterium with microscopic characteristics of Mycoplasma (formerly Eperythrozoon) wenyonii. Cattle Pract. 16:50-53.

Smith, J. A., M. A. Thrall, J. L. Smith, M. D. Salman, S. V. Ching, and J. K. Collins. 1990. Eperythrozoon-Wenyonii infection in dairy-cattle. J. Am. Vet. Med. Assoc. 196:1244-1250.

Stoffregen, W. C., D. P. Alt, M. V. Palmer, S. C. Olsen, W. R. Waters, and J. A. Stasko. 2006. Identification of a haemomycoplasma species in anemic reindeer (Rangifer tarandus). J. Wildl. Dis. 42:249-258. https://doi.org/10 $.7589 / 0090-3558-42.2 .249$.

Strugnell, B., and L. McAuliffe. 2012. Mycoplasma wenyonii infection in cattle. In Pract. 34:146-154. https://doi.org/10.1136/inp.e1550.

Strugnell, B. W., L. McAuliffe, K. Longmire, and J. Ellis-Iversen. 2011. Mycoplasma wenyonii associated with clinical signs in lactating dairy cows after herd-wide bluetongue vaccination. Cattle Pract. 19:75-80.

Tagawa, M., K. Matsumoto, and H. Inokuma. 2008. Molecular detection of Mycoplasma wenyonii and 'Candidatus Mycoplasma haemobos' in cattle in Hokkaido, Japan. Vet. Microbiol. 132:177-180. https://doi.org/10.1016/ j.vetmic.2008.05.006.

Tagawa, M., K. Yamakawa, T. Aoki, K. Matsumoto, M. Ishii, and H. Inokuma 2013. Effect of chronic hemoplasma infection on cattle productivity. J. Vet. Med. Sci. 75:1271-1275. https://doi.org/10.1292/jvms.13-0119.

Yuan, C. L., H. Ying, Z. H. Zhang, Z. B. Yang, J. G. Zhu, and X. G. Hua. 2011. Prevalence of Mycoplasma wenyonii infection on seven dairy farms in Shanghai, China. Wetchasan Sattawaphaet 41:179-184.

\section{Notes}

R. A. Schambow $\odot$ https://orcid.org/0000-0002-0968-2162

S. Bolin ๑ https://orcid.org/0000-0002-4488-6670

B. Norby @ https://orcid.org/0000-0001-6323-8735

P. L. Ruegg (i) https://orcid.org/0000-0002-7211-4512

This study was funded by USDA National Institute of Food and Agriculture (Washington, DC; project 2018-67030-28150).

The authors have not stated any conflicts of interest. 